\title{
DA ANÁLISE SISTÊMICA DO MOVIMENTO À ABORDAGEM DO GESTO EXPRESSIVO: A EXPERIÊNCIA DA TRADUÇÃO DA TRADIÇÃO NO PROCESSO DE CRIAÇÃO DO GRUPO SARANDEIROS
}

\author{
Gustavo Côrtes \\ Professor nos Cursos de Graduação em Dança, Educação Física e Fisioterpia da \\ Universidade Federal de Minas Gerais \\ Doutor em Artes da Cena pelo Instituto de Artes da Universidade de Campinas \\ Email: gustavocortesufmg@gmail.com
}

Este trabalho visa desenvolver, a partir do reconhecimento teórico advindo do campo de estudos da Abordagem Sistêmica do Gesto Expressivo, um percurso analítico para trabalhos interpretativos em danças brasileiras através da tradução cênica de manifestações tradicionais culturais. Desta forma, os diálogos entre as danças do Brasil e os estudos da Teoria da Tradução poderão fornecer novas possibilidades para trabalhos interpretativos. A relação de transposição artística entre os palcos teatrais e o campo de pesquisas será designada neste trabalho como Tradução da Tradição. A tradição, neste caso, seria como um meio organizador da memória coletiva existente nas festas e danças brasileiras tradicionais, e a tradução, os processos utilizados por artistas, coreógrafos, professores e demais interessados em trabalhos de criação em danças brasileiras. A análise sistêmica do gesto expressivo terá como norte a experiência da tradução da tradição no processo de criação do espetáculo Quebranto, do Grupo Sarandeiros da Universidade Federal de Minas Gerais.

Palavras-chave

Tradução. Tradição. Danças brasileiras. Análise Sistêmica do Gesto Expressivo.
This study aims to develop, from the field of Systemic Approach of Expressive Gesture, an analytical proposal for interpretive works in Brazilian dances. We propose the scenic translation of traditional cultural manifestations, through the Theory of Translation. The artistic transposition between theatrical stages and the research field will be designated as Translation of Tradition. Tradition is seen as an organizing medium for the collective memory existing in traditional Brazilian dances and festivals. Translation is conceived as the process used by artists, choreographers, teachers and others interested in creative work in Brazilian dances. The systemic analysis of the expressive gesture will be based on the experience of the translation of the tradition in the process of creation of the show Quebranto, from the Sarandeiros Group of the Federal University of Minas Gerais.

Keywords

Translation. Tradition. Brazilian Dances. Systemic Approach of Expressive Gesture 
Introdução

As reflexões presentes neste trabalho integram a tese de Doutorado em Artes da Cena realizado na UNICAMP e na Université de Paris VIII Saint Denis, finalizada em 2013, A tradução da tradição nos processos de criação em danças brasileiras: A experiência do Grupo Sarandeiros de Belo Horizonte 1 . Tal pesquisa buscou destacar um percurso metodológico para análises de trabalhos artísticos em danças brasileiras ${ }^{2}$ através da tradução cênica de manifestações tradicionais culturais ${ }^{3}$. De acordo com Guidére (2011), o objeto da Traductologia é a tradução em todas as suas manifestações, e significa, literalmente, a Ciência da Tradução. Desta forma, os diálogos entre as áreas de conhecimentos das Artes e os estudos da Teoria da Tradução poderão fornecer elementos para

1 O Grupo Sarandeiros, fundado em 1980, é um projeto institucional da Universidade Federal de Minas Gerais e conta com o apoio de sua Pró-reitoria de Extensão. Já realizou 15 turnês Internacionais e é um dos mais ativos grupos de pesquisa e representação das tradições brasileiras, através da música e da dança sobre o Brasil e no Brasil. Através de projetos educacionais, atua em várias escolas de Belo Horizonte com o ensino e a formação de grupos de danças populares brasileiras, inspirados nas manifestações folclóricas nacionais.

2 Cássia Navas (2003) considera que existe uma tríade de expressões que podem indicar três tipos de abordagens relacionadas ao termo danças brasileiras: Dança no Brasil, Dança do Brasil e Dança sobre o Brasil. No caso deste estudo, danças brasileiras são os trabalhos coreográficos de grupos que realizam suas obras artísticas através das pesquisas das manifestações populares brasileiras e no estudo das danças populares tradicionais existentes no Brasil, que servem de inspiração para trabalhos com danças sobre o Brasil. Tal tema é designado no plural pela diversidade que carrega, e indica uma relação tradicional com os modos de pensar, fazer e sentir os aspectos culturais de um povo, de uma determinada localidade em um tempo específico.

3 No caso do estudo de uma Tradição, na pesquisa de campo serão definidas as possíveis manifestações culturais que necessariamente deverão ser escolhidas a partir de critérios estabelecidos a priori: aceitação coletiva, tradicionalidade, dinamicidade e funcionalidade. Tal definição é estabelecida pela Carta da Comissão Nacional de Folclore (1995), item I, que delimita como tradicionais ou folclóricos apenas as manifestações que contenham tais critérios. trocas entre os campos de estudos, criando possibilidades de construções práticas e criativas na interpretação das danças brasileiras, traduzidas para a cena artística. Partindo então de uma motivação pessoal, como pesquisador das manifestações tradicionais brasileiras $e$ docente em diversas disciplinas de folclore e danças brasileiras na Universidade Federal de Minas Gerais (UFMG), artista e bailarino profissional especializado em danças brasileiras, buscou-se na pesquisa da tese estabelecer um diálogo pautado no estudo dos trabalhos sobre a cultura tradicional do Brasil e o que poderíamos chamar de análise sistêmica do movimento, na liminaridade entre prática e teoria.

O estudo das danças brasileiras, como parte do arcabouço cultural nacional, revela a importância de tal tema como possibilidade interpretativa nas artes da cena, nos mais distintos locais. A complexidade das experiências corporais e estéticas que surgem das expressões corporais presentes nas manifestações populares do Brasil, que se constituem como patrimônio imaterial do país, demanda pesquisa e profundo conhecimento de várias áreas e deve ser um tema interdisciplinar tratado por diferentes olhares.

Nas pesquisas sobre a criação artística, não há uma ordenação ou uma cronologia possível de ser elaborada como um processo único. Trata-se, principalmente, de uma possibilidade de apropriação teórica de estudos da Traductologia, para auxiliar pesquisadores artistas, envolvidos com atividades semelhantes, a refletirem sobre seus trabalhos. A produção de uma metodologia baseada na teoria da tradução apresenta amplas ferramentas que podem ou não estar presentes em maior ou menor intensidade nos processos criativos, na medida 
em que as análises e o próprio desenvolvimento do trabalho são sempre singulares, a partir do objeto de estudos escolhido. Ao tentar elaborar discursos referenciais sobre a sua prática, o artista pesquisador busca, a partir de sua experiência, compreender os aspectos intrínsecos que tornam o seu processo de criação diferente do outro. Este é o sentido do trabaIho realizado pelo Departamento de Dança na Universidade de Paris VIII Saint Dennis, através do grupo de pesquisas que faz estudos de análises de obras coreográficas, denominado de abordagem sistêmica do gesto expressivo, coordenado pela professora Dra. Christine Roquet $^{4}$

Por diversos motivos que vou explicar agora, preferi chamar esse campo de pesquisa: Abordagem Sistêmica do Gesto Expressivo. A abordagem sistêmica considera a corporeidade como um "supra sistema" cujos subsistemas - somático, perceptivo, psíquico, entre outros - estão em interação constante. Trata-se aqui de uma visão holística do "corpo", e de um pensamento do processo que evita hierarquizar as noções de central/ periférico ou profundo/superficial, por exemplo, e que inclui o observador. A neutralidade aqui é impossível; a leitura do gesto do outro me remete à minha própria capacidade de olhar e exclui o juízo de valor. O espectador faz-se espectador e a leitura do gesto é uma "leitura do gesto em relação" com o outro, com o espaço, com o meio-ambiente, etc. Se tivermos que analisar ou observar um detalhe, não poderemos perder de vista que a percepção afirma que "não existe o «homem interior», [que] o homem está no mundo, [que] é no mundo que ele se conhece [e que] o mundo é aquilo que percebemos". (Roquet, 2011, p. 13).

4 A pesquisadora Dra. Christine Roquet era a Coordenadora do Departamento de Estética, Filosofia, Dança e Música da Universidade de Paris VIII Saint Dennis e apresentou os estudos sobre a análise do movimento durante o curso realizado na Universidade de Paris VIII, entre os meses de novembro e abril de 2012. As análises estão presentes também no artigo: $\mathrm{Da}$ análise do movimento à abordagem sistêmica do gesto expressivo. Revista O Percevejo, vol. 3, n. 1, 2011.
Assim, o trabalho sobre análise do movimento através de uma abordagem do gesto se apresenta como uma ferramenta acadêmica para realização de reflexões sobre obras coreográficas. A pesquisa dos processos de criação artística em dança, inspirada nas tradições e na memória coletiva das festas e folguedos populares, decorre de vários questionamentos que emergiram a partir do trabalho de extensão universitária realizado pelo pesquisador deste artigo junto ao Grupo Sarandeiros da UFMG, desde 1997. Neste sentido, discutir as possibilidades de análise de movimentos gestuais e de formas de expressão existentes em danças brasileiras, sem que isso seja um resgate da cultura nacional, torna-se fundamental neste trabalho. No cruzamento de elementos como as danças, festas, cantos e informações derivadas de processos culturais híbridos, grupos tradicionais buscam na memória coletiva uma forma de manterem vivas as representações de fatos ou de acontecimentos importantes ocorridos na comunidade. Toda tradição utiliza-se da história como uma ponte temporal legitimadora das ações e do espaço como cimento da coesão do grupo. Percebe-se que o termo híbrido diz respeito a processos dinâmicos de grupos tradicionais que, nos tempos atuais, são tensionados a realizar combinações nem sempre conscientes pelos seus integrantes, que determinam novas estruturas, objetos e práticas. Neste sentido, podemos afirmar que mesmo em grupos tradicionais as traduções da tradição são realizadas de forma espontânea, pois a hibridização acontece de forma aleatória, como decorrência inesperada de processos migratórios, intercâmbios culturais, econômicos e turísticos (Canclini, 2003).

Os aspectos de tradução para a reelaboração total ou parcial das danças tradicionais são 
fundamentais para que tais trabalhos artísticos possam ser considerados como processos de criação, e não uma reprodução ou um resgate, ou uma cópia da tradição. Partindo para o foco deste trabalho, como se estabelecem então as pontes de criação entre invenção e produção cênica a partir de matrizes existentes nas manifestações populares brasileiras, que resultam em trabalhos da cena? No caso específico das danças brasileiras, como se organizam os trabalhos e como são elaboradas análises metodológicas na transposição artística dos trabaIhos realizados pelos pesquisadores artistas, do campo de pesquisas para o palco?

\section{A Tradução da Tradição:} Metodologia baseada na experiência

Os estudos da teoria interpretativa, construídos especialmente em pesquisas sobre a Literatura e suas possibilidades de apropriação, têm ampliado suas pesquisas para outras áreas do conhecimento de forma multidisciplinar. Tais estudos tratam especificamente de temas relacionados aos trabalhos de tradução entre sistemas simbólicos diversos, como por exemplo, quando se traduz um romance para um filme, um poema épico para uma revista em quadrinhos, ou se cria uma coreografia a partir de uma pesquisa de movimentos, o que reforça o aspecto epistemológico interdisciplinar do termo. A metodologia definida como Tradução da Tradição ${ }^{5}$ busca estabelecer pontes nos pro-

5 Todo o trabalho sobre a Metodologia da Tradução da Tradição foi defendido no doutorado do autor deste artigo: $A$ tradução da tradição nos processos de criação em danças brasileiras: A experiência do Grupo Sarandeiros de Belo Horizonte. Tese de Doutorado - Instituto de Artes da Universidade de Campinas, Campinas, 2013. cessos tradutórios estabelecidos entre a pesquisa de campo e a interpretação de tal estudo para ser utilizado em qualquer ambiente cênico. Neste caso, campo será entendido como um lócus que oferece várias possibilidades para a realização de um trabalho de tradução, como, por exemplo, estudos de movimentos realizados em festas e danças tradicionais, relatos de entrevistas, dramaturgias retiradas de estórias orais e literárias, etc. As pesquisas de campo buscarão especialmente, dentre outras finalidades, a elaboração de um texto a partir do qual o trabalho tradutório resultará na realização de um percurso de criação em dança.

Eco (2007) chama a atenção para a diversidade de casos, dentro do processo de tradução de uma obra, que se apresentam como resultado de uma Adaptação, como por exemplo, a utilização de um trecho de um poema (texto fonte) em uma ação coreográfica (texto de destino). Esta possibilidade é descrita pelo autor como uma interpretação por manipulação, ou uma Transmutação. Assim, a partir dos aspectos singulares ligados à manipulação do texto fonte, a adaptação é mediada pelo tradutor não apenas na sua forma, mas na sua intencionalidade e interpretação. Nesta transformação da substância, entre sistemas simbólicos diferentes, o tradutor pode optar por licenças poéticas para produzir um determinado efeito no plano da expressão, estabelecendo determinadas concessões e violando, por vezes, o texto referência. $O$ autor denominou tal aspecto de Reelaboração parcial e radical, e a diferença entre elas estaria mensurada em uma escala de licenças:

Existem alguns casos de reelaboração parcial, nos quais os tradutores, para permanecerem fiéis ao sentido profundo e ao efeito que o texto devia produzir no plano da expressão, 
concediam-se e deviam conceder algumas licenças, violando, por vezes, a referência. Mas há ocasiões de uma reelaboração mais radical, que se dispõe em uma escala, por assim dizer, de licenças, até chegar àquele limiar além do qual não há mais nenhuma reversibilidade (Eco, 2007, p. 353).

No trabalho dos mais variados artistas, autores de teatros, coreógrafos, escritores, que desenvolvem processos de criação e criam novos conhecimentos no cinema, na música, na literatura, no teatro e na dança, podem ser encontrados inúmeros exemplos de uma adaptação, ou de reelaboração parcial ou total a partir de uma Tradução da Tradição. Tais processos são cotidianamente reestruturados nas suas mais diversas formas de construção, a partir de novas experimentações. Muitos destes trabalhos têm como foco produções artísticas traduzidas de situações vivenciadas nas manifestações tradicionais brasileiras, e apresentam um papel relevante na interpretação da diversidade cultural existente no Brasil. Tal fato explicaria a necessidade de compreender, como, em que nível e de que maneira os estudos da Traductologia poderiam auxiliar na compreensão de como se organizam tais trabalhos.

Assim, buscar uma aproximação teórica entre a Teoria Interpretativa e as Artes da Cena parte de dois pressupostos principais, inspirados na atuação do tradutor-artista nos processos de interpretação criadora de uma tradução: 1- Toda tradução é uma forma de interpretação pessoal; 2- Toda tradução é uma possibilidade de escolhas dentre várias possibilidades. Desta forma, podemos dizer que uma tradução, sob a ótica das artes, pode expressar uma forma libertária e criativa do artista, trazendo novos elementos e dinamismo aos elementos tradicionais encontrados em uma pesquisa de campo, abrindo novas possibilidades de construção de conhecimentos. O trabalho, neste caso, não deve ser interpretado como uma reprodução fiel ao que foi pesquisado, mas deve oferecer, como proposição artística, um novo caminho de compreensão a partir do processo de tradução. O processo para construção de um trabalho coreográfico a partir de uma pesquisa de campo deverá trazer diferenças em relação ao autêntico, para que as apresentações tragam algo de novo no âmbito das artes da cena. Um processo tradutório, a partir de uma teoria interpretativa, designa uma percepção específica, uma prática singular que pode ser encontrada em diversas ações baseadas na experiência, traduzida por um emissor e interpretada por um receptor. Dentre estas ações, como por exemplo, a tradução de uma obra literária de uma língua à outra, a tradução simultânea de um discurso realizado, o subtítulo de um filme, a adaptação de uma obra literária para a cena teatral, ou a tradução cênica de manifestações tradicionais em coreografias de danças brasileiras, encontram-se possibilidades sistêmicas de análises diversas. Ao manipular sistemas simbólicos diferentes, o tradutor abre possibilidades para que o trabaIho interpretativo no campo artístico possa ser desenvolvido com criatividade, rompendo com a noção de reprodução.

Especificamente com relação a este trabaIho, que traduz novas possibilidades de sentido, equivalência e fidelidade ao texto fonte em um trabalho coreográfico, a tradução dará sustentação a todo processo e definirá muitos critérios de análise relacionados a trabalhos com as danças brasileiras. Entretanto será somente através da análise da prática, na relação que se estabelece entre as pesquisas de campo e 
os processos de Tradução, que tais elementos poderão ser identificados em um trabalho artístico, e nunca serão iguais ao original, pois de acordo com Ladmiral (1994):

Dentro da prática, a tradução será sempre parcial. Como todo ato de comunicação, ela comportará certo grau de entropia, outra forma dita, certa perda de informação. O trabalho do tradutor consiste em escolher o menos mal; ele deve distinguir o que é essencial daquilo que é acessório. Suas escolhas de tradução serão orientadas por uma escolha fundamental concernente à finalidade da tradução [...] (Ladmiral, 1994, p. 18-19, tradução nossa) .

Isso significa que toda obra artística, ao optar por determinados aspectos que foram encontrados e traduzidos a partir de uma pesquisa, por si só já apresenta aspectos de infidelidade em relação ao todo. E é exatamente nesta liminaridade que existem possibilidades de análise de um processo de criação, cuja decisão dependerá dos objetivos que o pesquisador artista terá frente à sua obra.

Da análise do movimento à abordagem sistêmica do gesto expressivo: A experiência do espetáculo Quebranto, com o Grupo Sarandeiros de Minas Gerais

Os estudos propostos pela Dra. Christine Roquet, desenvolvidos no Departamento de Dança na Universidade de Paris VIII Saint Dennis, pressupõem quatro diferentes níveis

6 Dans La pratique, La traduction será bien sur toujours partille. Comme tout acte de communication, elle comportera un certain degree d'entropie, autrement dit une certain désperdition d'information. Le métier de traducteur consiste a choiser le moindre mal; il doit distinguir ce qui est essential de ce qui est accssoire. Ses choix de traduction seront orientes par um choix fondamental concernant La finalité de La traduction[...]. de análises sobre processos coreográficos. De acordo com a pesquisadora, pode-se observar e analisar o gesto humano conforme eixos diferentes (ou níveis) e com vários objetivos. As perspectivas de análise podem ser diferenciadas conforme as maneiras de abordar a questão do "sentido" do gesto:

- O Nível da narratividade: A coreografia ou o espetáculo conta uma história, e a análise se dá a partir daquilo que é criado diretamente de uma anedota (tipologia de personagens, colocação em cena de situações a partir de uma mimese ou teatralização da personagem), por meio do gesto;

-O Nível da "mis en scène", ou do estar em cena: A composição é analisada como uma construção que engloba a relação de todos os arranjamentos, desde a relação do intérprete com o espaço dinâmico e o simbólico da cena, até a utilização da música, ou de um pedaço da música, ou da ausência desta como estruturação do tema a ser desenvolvido;

- O Nível da Cenografia: As análises são realizadas a partir do conjunto de elementos intrínsecos das coreografias, ou da ausência deles: local cênico (cenário), luz, figurinos, adereços e maquiagem e a relação do dançarino com o espaço;

- O Nível da Interpretação: A análise se faz diretamente em relação ao jogo do intérprete em cena, cuja atuação resulta em uma maneira particular de produzir um gesto ou reproduzir um movimento. Este nível de interpretação diz respeito ao trabalho do dançarino, a partir de um projeto definido previamente;

Os níveis de análises propostos fazem parte de um campo de observação, que podem auxiliar o pesquisador artista a aprofundar sobre as questões teóricas inerentes à percepção da sua obra. A importância de uma análise deta- 
Ihada está sintonizada com a necessidade de se encontrar perguntas e respostas dentro de um novo campo artístico-acadêmico, que busca na diversidade de fazeres, a riqueza do conhecimento produzido.

Segundo Roquet (2011, p. 13):

Certamente, o nosso campo "científico" é ainda bastante jovem e está à procura de suas próprias "insígnias de nobreza" teóricas, com dificuldade de fixar seus pressupostos epistemológicos. Demos-lhe tempo... Porque, se as demais artes são objetos de uma "pesquisa fundamental", então, por que não o gesto dançado? Quais são as razões sociais, culturais, políticas que fundamentariam tal recusa? Em nossas sociedades ocidentais, onde a circulação do poder é feita pelo logos - a razão amparada pela linguagem é indispensável para o bailarino, artista do gesto, refletir, falar, nomear seu próprio trabalho.

Cruzando tal proposta de análise com o trabalho deste artigo, pode-se argumentar que todos estes níveis se relacionam aos processos de criação, a partir do olhar do artista no campo de pesquisa. Desta forma, o texto que surge sobre o estudo de uma tradição passa a oferecer amplas possibilidades de abstração e inspiração na construção dos trabalhos poéticos traduzidos para a cena, a partir de diferentes referenciais existentes na pesquisa de campo. A tradução atravessa as estruturas cênicas analisadas em diversas configurações dramatúrgicas, que se manifestam como protocolos de criação dos artistas responsáveis pela autoria dos espetáculos. Todo o processo de estruturação cênica está diretamente atrelado à poética daquele que cria a obra artística, a partir de uma escolha pessoal, na figura do diretor, do coreógrafo ou do intérprete. De fato é tradição considerar o gesto como apoio, reforço ou substituto da palavra. O sentido de um gesto não pode ser dissociado do seu contexto. Assim, como para os gestos do quotidiano, o gesto do bailarino não pode ser reduzido a um signo, legível e decifrável, pois depende de todo um contexto.

O estudo de caso deste artigo estabelece pontes entre prática e teoria nos trabalhos com danças brasileiras e teve como referencial a análise de um dos espetáculos produzidos pelo Grupo Sarandeiros, "Quebranto", de 2008. Nesta análise surge a possibilidade de criação de uma reflexão sobre a tradução da tradição, que, na elaboração deste trabalho coreográfico, teve como norte os estudos das histórias Yorubás no Brasil. Neste sentido, a análise do espetáculo Quebranto será realizada dentro do modelo proposto pelo Departamento de Estética, Filosofia, Dança e Música, da Universidade Paris VIII, através da Abordagem Sistêmica do Gesto Expressivo.

Ao nível da narratividade, o espetáculo Quebranto conta histórias, baseadas nos mitos das divindades trazidas para o Brasil pelo povo africano. As lendas mitológicas dos grandes Reis que se tornaram Orixás (Ori = Cabeça física e astral + Ixá = guardião) são a base para compreensão das coreografias que compõem o espetáculo. Na interpretação dada ao show, as figuras dos Orixás são traduzidas como elementos energéticos existentes no universo, onde cada um representa uma força da natureza. Partindo desta leitura, na tradução de alguns mitos relacionados à vida das divindades, buscou-se a interpretação das forças elementares oriundas da água, da terra, do ar e do fogo relacionadas aos poderes de cada mito. Na origem da adoração aos deuses estão os povos negros que, na maioria das nações existentes na África anteriores à era cristã, co- 
nheciam os seus ancestrais e os relacionavam com as energias de todos os elementos da natureza. As histórias mitológicas dos Orixás se fixaram no Brasil principalmente dentro dos terreiros de Candomblé. Esta religião, que tem por base a "anima" (alma) da Natureza, foi desenvolvida no Brasil com o conhecimento dos sacerdotes africanos que, escravizados e trazidos da África para o Brasil entre 1549 e 1888, trouxeram consigo os seus Orixás/Inquices/ Voduns que faziam parte do cotidiano de sua cultura (Candomblé, 2013). Tendo como norte tais dados iniciais, o espetáculo foi concebido a partir daquilo que é criado diretamente de um mito, o que proporcionou elementos para a composição tipológica dos personagens e a colocação em cena de situações dramatúrgicas específicas para cada coreografia, elaboradas a partir da construção gestual representativa para cada Orixá, por meio das matrizes dos movimentos.

Ao Nível da "Mis en Scène", a composição pode ser analisada como uma construção que engloba a relação de todos os elementos coreográficos para a cena, desde a relação do intérprete com o espaço dinâmico e simbólico do palco, até a criação da música, feita especialmente para a obra, cujos cantos criados utilizaram das narrativas de cada mito encenado. A construção de uma trilha sonora específica para o trabalho foi um fator extremamente relevante para a realização de um processo de criação autoral e singular.

Ao Nível da Cenografia, as análises foram realizadas a partir do conjunto de elementos que buscaram criar relações diretas com a dramaturgia desenvolvida em cena: cenário, luz, figurinos, adereços e maquiagem. Todos estes elementos foram desenvolvidos levando em consideração o roteiro elaborado a partir da narratividade. Para a construção do espetáculo, o cenário foi produzido levando em consideração a ideia de céu e de terra, com a apropriação das histórias que buscam relacionar os deuses e os seres humanos. A rampa utilizada como cenário, desenhada em forma de concha e meia lua, busca formatar o espaço real e simbólico de apresentação, tanto em relação ao espectador quanto em relação à divindade interpretada. Para cada um dos mitos foram criados figurinos e realizado um projeto de iluminação específico, no qual as cores eram fundamentais para o entendimento da relação de cada orixá com os elementos da natureza: água, terra, fogo e ar.

Finalizando, ao Nível da Interpretação, a análise se faz diretamente em relação ao trabalho do intérprete em cena, cuja atuação decorre de possibilidades relacionadas a sua vivência pessoal e à maneira de reproduzir um movimento. Este nível de interpretação diz respeito à análise que cada intérprete fará na visão de seu desenvolvimento com o processo coreográfico e na sua tradução do trabalho em cena.

A construção do espetáculo Quebranto foi realizada a partir de um roteiro previamente estabelecido e que levou dois anos para ser concluído. O Trabalho procurou quebrar com preconceitos sobre as divindades afro-brasileiras cultuadas no país. Com ensaios de 10 horas semanais e um grupo de 26 dançarinos que fizeram parte da estreia, a obra nasceu com a intenção de valorizar e divulgar a cultura afro-brasileira, tendo como norte os mitos relacionados aos Orixás e os ensinamentos do Candomblé. Tema raramente trabalhado pelas companhias de danças brasileiras, fruto de desconhecimento e preconceito, tal assunto foi durante muitos anos proibido pela igreja 
católica e criminalizado mesmo por alguns governos. Ao realizar o registro vídeografico da obra, o grupo busca possibilidades de valorização da cultura dos Orixás no Brasil através da arte. Desta forma posta, a ideia de tradução da tradição remonta ao sentido de valorizar, divulgar e reconhecer como parte intrínseca da cultura brasileira as manifestações tradicionais dos povos africanos no Brasil.

Exemplarmente vamos analisar uma coreografia do espetáculo, para entendermos as relações entre a teoria e a prática:

\section{Coreografia Exu: O Livre Arbítrio}

A primeira dança dos Orixás apresentada no espetáculo mostra a interpretação de Exu, o mensageiro dos Orixás. A leitura do mito de Exu descrito abaixo apresenta uma revelação importante para a dramaturgia estabelecida no espetáculo, e explica por que Exu está presente nas encruzilhadas e também o porquê de sua relação próxima a Oxalá:

Exu ganha o poder sobre as encruziIhadas

Exu não tinha riqueza, não tinha fazenda, não tinha rio, não tinha profissão, nem artes, nem missão. Exu vagabundeava pelo mundo sem paradeiro. Então um dia, Exu passou a ir à casa de Oxalá. la à casa de Oxalá todos os dias. na casa de Oxalá, Exu se distraía, vendo o velho fabricando os seres humanos. Muitos e muitos também vinham visitar Oxalá, mas ali ficavam pouco, quatro dias, oito dias, e nada aprendiam. Traziam oferendas, viam o velho orixá, apreciavam sua obra e partiam. Exu ficou na casa de Oxalá dezesseis anos. Exu prestava muita atenção na modelagem e aprendeu como Oxalá fabricava as mãos, os pés, a boca, os olhos, o pênis dos homens, as mãos, os pés, a boca, os olhos, a vagina das mulheres. Durante dezesseis anos ali ficou ajudando o velho orixá. Exu não perguntava. Exu observava. Exu prestava atenção. Exu aprendeu tudo. Um dia Oxalá disse a Exu para ir postar-se na encruzilhada por onde passavam os que vinham à sua casa. Para ficar ali e não deixar passar quem não trouxesse uma oferenda a Oxalá. Cada vez mais havia mais humanos para Oxalá fazer. Oxalá não queria perder tempo recolhendo os presentes que todos Ihe ofereciam. Oxalá nem tinha tempo para as visitas. Exu tinha aprendido tudo e agora podia ajudar Oxalá. Exu coletava os ebós para Oxalá. Exu recebia as oferendas e as entregava a Oxalá. Exu fazia bem o seu trabalho e Oxalá decidiu recompensá-lo. Assim, quem viesse à casa de Oxalá teria que pagar também alguma coisa a Exu. Quem estivesse voltando da casa de Oxalá também pagaria alguma coisa a Exu. Exu mantinha-se sempre a postos guardando a casa de Oxalá. Armado de um ogó, poderoso porrete, afastava os indesejáveis e punia quem tentasse burlar sua vigilância. Exu trabalhava demais e fez ali a sua casa, ali na encruzilhada. Ganhou uma rendosa profissão, ganhou seu lugar, sua casa. Exu ficou rico e poderoso. Ninguém pode mais passar pela encruzilhada sem pagar alguma coisa a Exu. (Prandi, 2001, p. 40-41).

$\mathrm{Na}$ leitura desse mito, surgem elementos narrativos para a elaboração de uma coreografia que apresenta diversos caminhos e a livre escolha dos seres humanos para desenvolverem suas vidas. Na cena, os dançarinos que interpretam os filhos de Exu estão sempre em encruzilhadas, e sentem-se presos aos prazeres da vida e às imposições espirituais. Têm desejos intensos e usam de sensualidade e perspicácia para atingir os seus objetivos carnais. Ao nível "mis en scène", na leitura do arquétipo de Exu, os gestos estão relacionados à sexualidade, aos vícios humanos, ao livre arbítrio dos prazeres. Ao nível da narratividade, a cena demonstra a dualidade de Exu: se a pes- 
soa deseja seguir os caminhos das bebidas, drogas, prazeres mundanos, libertinagens, o mensageiro dos deuses não vai se posicionar contra, pois ele não diferencia o bem do mal; mas se ela deseja abandonar os vícios, ele a ajudará. $\mathrm{Na}$ análise de um dos elementos cenográficos, a rampa utilizada no espetáculo trará o único momento na qual os dançarinos interpretam outras entidades além dos Orixás, com a representação das pombagiras, espíritos de cemitérios e de encruzilhadas, colaboradores de Exu. Ao nível da interpretação, a expressão dos dançarinos foi trabalhada através do sarcasmo de Exu, rindo das derrotas e chorando as alegrias, pois para ele não existe o certo e o errado, e sim o desejo. Na análise final dessa coreografia, Exu ri de nosso destino, pois as encruzilhadas estão presentes nas nossas vidas em tudo que nos rodeia, e somos obrigados a ter escolhas.

\section{Conclusão}

No processo de Tradução da Tradição, os movimentos de danças das manifestações culturais tradicionais, reorganizados pelo olhar singular do artista e, teorizados pelo conhecimento crítico de um pesquisador, podem auxiliar a desconstruir uma imagem de não dinamicidade das tradições. Nos trabalhos em grupos de danças brasileiras, a forma como são realizadas as pesquisas de campo, assim como as escolhas feitas durante o percurso em um trabalho de Tradução da Tradição, determinam uma metodologia de ação nos trabalhos de criação, diferentes em cada grupo e em cada produção. Todo processo metodológico será resultado de múltiplas negociações entre os integrantes do projeto e resultará em uma obra original. Desta forma, o artista-pesquisador realiza um trabalho poético através de uma interpretação pessoal e subjetiva a partir de sua experiência, pois ao manipular o texto fonte elaborado sobre uma pesquisa de campo, ele cria uma obra única, original e singular. Sendo assim, a teoria da interpretação, em sua relação com a produção em Artes da Cena, oferece um percurso metodológico de tradução de uma tradição que deve apresentar três etapas de pesquisa:

1- Análise do objeto a traduzir (a Fonte);

2- Análise do trabalho do artista-tradutor (o Processo);

3- Análise da operação de tradução (o Produto).

Desta forma, qualquer obra coreográfica com as danças brasileiras, que passa por um processo de transmutação ao manipular elementos encontrados nas tradições culturais para se transformar em coreografias, pode ser analisada sob estes aspectos. A pesquisa de campo marcará o trajeto inicial da obra instaurado pelo estudo da fonte, cujos conteúdos definirão o percurso de todo o trabalho coreográfico, em maior ou menor intensidade de tradução. A organização do trabalho e o eixo estrutural da composição na realização da obra são elementos singulares existentes em todo o processo, a partir de uma escolha pessoal mediada pelo artista. Será através de todo o processo de criação, a repetição, os ensaios, a memorização de todos os detalhes e a concretude da obra, que o artista pesquisador apresentará o produto da obra, de seu estado de fonte para o resultado final. Na metodologia da Tradução da Tradição poderemos argumentar que todo o trabalho artístico construído será caracterizado por certa instabilidade, por ser um processo mediador, não apenas entre 
duas culturas espacialmente distantes, mas também entre momentos históricos muitas vezes diversos. No processo de criação não se fixam momentos cristalizados, identidades absolutas ou reproduções de imagens concretas, mas se apontam continuamente processos de diferenciação e identificação pessoal do artista, o que faz com que cada tradução de cada tradição pesquisada seja diferente uma da outra, mesmo que o tema escolhido seja igual. Neste sentido, a avaliação dos processos tradutórios, a partir da análise sistêmica dos gestos, podem ser verificados no decorrer de toda criação em todos os níveis de estruturação, em um constante devir. É neste espaço simbólico e temporal, caracterizado pelas escolhas do artista-pesquisador, que será desenvolvido o trajeto da interpretação no trabalho artístico de tradução. A utilização dos conceitos da análise sistêmica do gesto expressivo como possibilidade de construção de um arcabouço teórico, na avaliação dos processos artísticos produzidos no campo das Artes da Cena, abre possibilidades para novos estudos e estabelece novas relações dialógicas entre uma pesquisa acadêmica e a obra artística.

\section{Referências}

CANCLINI, Néstor García. Culturas Híbridas: estratégias para entrar e sair da modernidade. 4. ed. São Paulo: EDUSP, 2003.

COMISSÃO NACIONAL DE FOLCLORE. Carta do Folclore Brasileiro. Disponível em: http:// www.fundaj.gov.br/geral/folclore/carta.pdf Acesso em 13 outubro 2011.
CÔRTES, Gustavo. A tradução da tradição nos processos de criação em danças brasileiras: A experiência do Grupo Sarandeiros de Belo Horizonte. Tese de Doutorado - Instituto de Artes da Universidade de Campinas, Campinas, 2013.

CÔRTES, Gustavo; SANTOS, Inaicyra Falcão dos; ANDRAUS, Mariana Baruco Machado. Rituais e Linguagens da Cena: Trajetórias sobre Corpo e Ancestralidade. Curitiba: Editora CRV, 2012.

ECO, Umberto. Quase a mesma coisa: experiências de tradução. Rio de janeiro: Editora Record, 2007.

LADMIRAL, Jean-René. Traduire: théorèmes pour lah traduction. Paris: Gallimard, 1994.

LEDERER, Marianne. La traduction aujourd'hui: le modèle interprétatif. Paris: Hachette, 1994.

NAVAS, Cássia. Dança brasileira no final do século XX. In Dicionário SESC, A Linguagem da Cultura. Org. Newton Cunha. São Paulo: Perspectiva, 2003.

ROQUET, Christine. Da análise do movimento à abordagem sistêmica do gesto expressivo. Revista O Percevejo, vol. 3, n. 1, 2011. Disponível em: http://www.seer.unirio.br/index. php/opercevejoonline/article/view/1784/1518. Acesso em: 03 out. 2013.

PRANDI, Reginaldo. Mitologia dos Orixás. São Paulo: Companhia das Letras, 2001.

Espetáculo: Quebranto: A Dança dos Orixás Registro em DVD - Grupo Sarandeiros, 2008. 
Recebido: 15/04/2017

Aprovado: 30/06/2017 